\title{
Hackethal Bundle Nailing with Intramedullary Elastic Nails in the Treatment of Two- and Three-Part Fractures of the Proximal Humerus: Initial Experience at Al Razi Hospital, Kuwait
}

\author{
Wieslaw Pospula Tarek Abu Noor \\ Department of Orthopedics, Al Razi Hospital, Kuwait
}

\section{Key Words}

Proximal humerus fracture $\cdot$ Minimally invasive fixation

\begin{abstract}
Objective: To present the clinical and radiological results of a minimally invasive technique, the fixation of two- and three-part fractures of the proximal humerus according to the Neer Classification System, using the intramedullary bundle-wiring Hackethal technique. Subjects and Methods: The operations were performed with the Hackethal technique (use of elastic titanium nails, Synthes) on 17 patients ( 8 males and 9 females) with two- and three-part fractures of the proximal humerus. In cases of two-part fracture only, intramedullary titanium nails were used while for three-part fractures, percutaneous cannulated screws were used to fix the greater tuberosity, followed by intramedullary insertion of titanium elastic nails. The clinical results were assessed using the Constant score and radiological assessment including the union and alignment of the proximal humerus. Preoperative and postoperative CT scans were performed along with 3D reconstruction in all cases for diagnostic and prognostic significance. Results: All fractures united in an average period of 12 weeks (range 10-17 weeks). In all patients, a good to excellent range of motion of the shoulder, and good to excellent muscular power and alignment were not-
\end{abstract}

ed. The Constant score amounted to 81 points (range 64-98 points). There was no secondary loss of fixation and migration of implants. Conclusion: In cases of two-part fracture of the proximal humerus, the minimally invasive Hackethal technique alone and in cases of three-part fracture, the same technique with percutaneous cannulated screws provided excellent clinical and radiological results with a minimal risk of complication. It is an important alternative to open reduction and internal fixation of these difficult fractures.

Copyright $\odot 2009$ S. Karger AG, Basel

\section{Introduction}

Treatment of proximal humeral fractures remains a subject of debate, especially in older patients. Published randomized and comparative studies review a wide range of treatment methods $[1,2]$. The problems involved in treatment decisions include type of fracture, bone quality and general condition of the patient. Several methods, including conservative treatment, variable forms of fixation, and hemiarthroplasty have been proposed, but the long-term results have not always been satisfactory, and a new interest in finding a better therapeutic solution has been observed in recent years [3-9]. The introduction of locking plates with better fixation stability has improved

\section{KARGER}

Fax +4161306 1234

E-Mail karger@karger.ch

www.karger.com
(C) 2009 S. Karger AG, Basel

1011-7571/09/0184-0284\$26.00/0

Accessible online at:

www.karger.com/mpp
Wiseslaw Pospula, $\mathrm{MD}, \mathrm{PhD}$

Al Razi Orthopedic Hospital

PO Box 4235, Safat 13043 (Kuwait)

Pager +965 9917 4515, Tel. +965 9986 2485, Fax +965 24822240

E-Mail pospulawieslaw@hotmail.com 

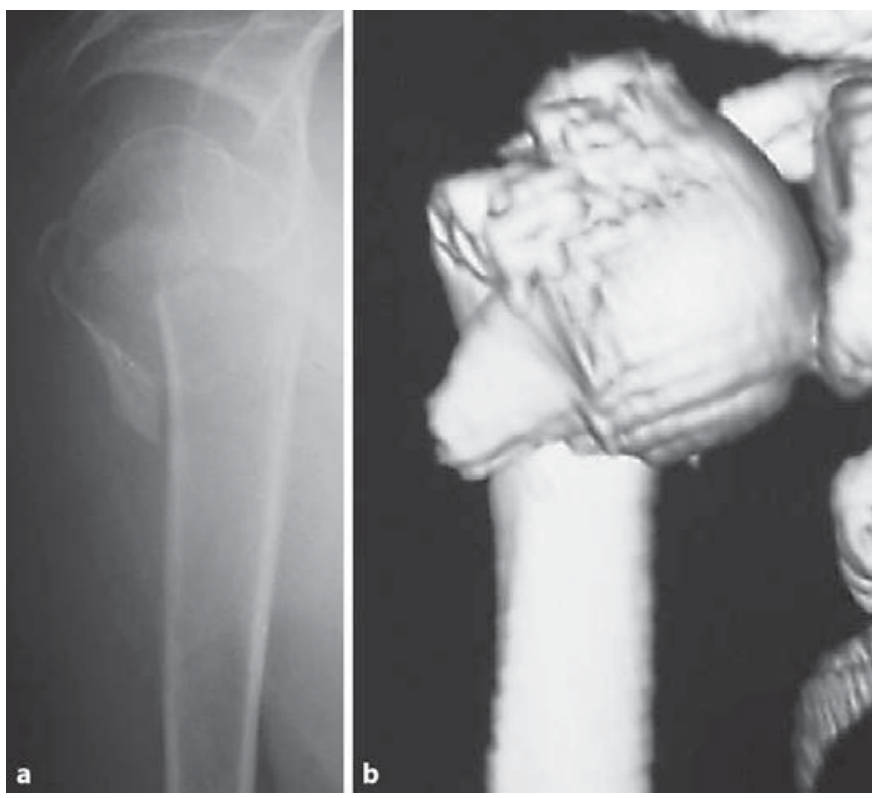

Fig. 1. CT with $3 \mathrm{D}$ reconstruction of the fracture. a Initial X-ray. b The same case visualized in $3 \mathrm{D}$ reconstruction.

the results of fixation, but since even these implants may fail, other fixation devices have been proposed [10]. The question whether stiff and rigid implants are better than elastic implants in these fractures remains unanswered and reports on experimental studies have not given unequivocal results [11]. In this study, indirect reduction using manipulation and the joystick technique combined with intramedullary fixation following the Hackethal method was applied. We report our results in an initial series of 17 patients treated with this technique.

\section{Subjects and Methods}

Seventeen patients, 8 male and 9 female patients, average age 44.9 years (range: 18-69) with two- and three-part fractures of the proximal humerus according to the Neer Classification System were treated using intramedullary bundle fixation with 3 elastic titanium nails (Synthes) following the Hackethal method [12]. In most cases, the cause of fracture was a fall from a standing height. Fractures were classified according to Neer's criteria as two- and three-part fractures [13]. CT scans with 3D reconstruction (fig. 1) enabled us to classify fractures according to the classification proposed by Edelson et al. [14]. The fracture was reduced by traction and manipulation with a Schanz screw (joystick technique) and monitored using an image intensifier. In cases of two-part fractures, only intramedullary titanium nails were used. In three-part fractures, percutaneous cannulated screws were used to fix the greater tuberosity, followed by intramedullary insertion of tita-
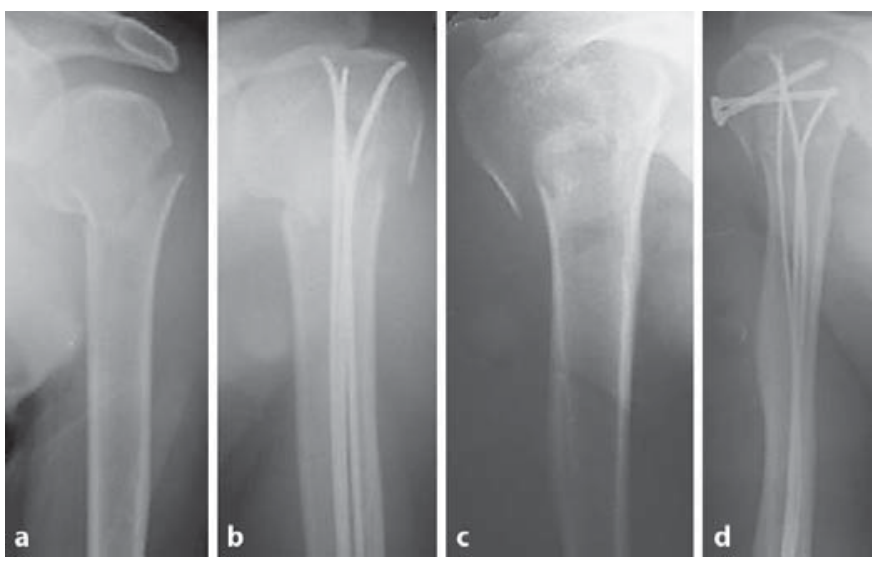

Fig. 2. Examples of fixation of two- and three-part fractures. a Initial X-ray of two-part fracture. b Postoperative X-ray of a two-part fracture. c Initial X-ray of a three-part fracture. d Postoperative X-ray of a three-part fracture.

nium elastic nails (fig. 2). The nails were inserted through a window on the posterior aspect of the distal humerus. The tip of each elastic nail was bent slightly to engage the humeral head in a divergent way. After the nails were well seated, they were bent and cut distally. The fragments of bony window were impacted to prevent distal migration of the implants. Usually, 3 tightly fitting elastic titanium nails having a diameter $2-3 \mathrm{~mm}$, depending on the cross-section diameter of the medullary cavity, were used to assure the rotational stability of the construct. Initially, after surgery, the operated arm was immobilized on a sling. Starting from the second week, gradual gentle passive and assisted active mobilization was started. The progress of bone union and physiotherapy was monitored at 3-week intervals until the patient had a good range of motion of the affected shoulder, and progress of union was visible on the X-ray (fig. 3). Routinely, a postoperative CT scan with $3 \mathrm{D}$ reconstruction of the operated shoulder was done to better assess the position of the implants, the accuracy of reduction, and the risk of secondary displacement (fig. 4). Alignment was defined as neutral, valgus or varus. The Constant score was used to assess the functional result of the treatment [15]. All surgeries were performed by the senior author (W.P.); follow-up assessment was done by the second author (T.A.N.), who was not involved in surgical procedures. Patients were examined at each follow-up visit, and the final clinical score was assessed at the last follow-up. The patients were followed for 13.2 months.

\section{Results}

All fractures united during an average period of 12 weeks. The final Constant score was 80.3 points (range: 64-98). The alignment was normal in 13 patients; 2 cases were varus and 2 cases were valgus. The alignment did not affect the clinical result or union. There were no cas- 
Fig. 3. Progress of the union of a proximal humeral fracture. a Initial X-ray. b Postoperative X-ray. c Progress of union with callus formation.
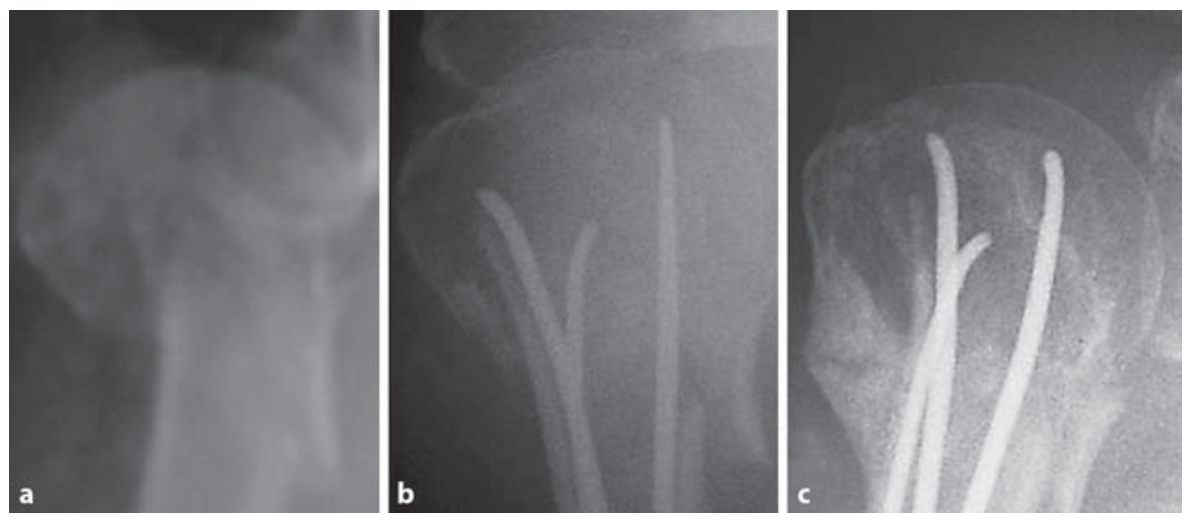

Table 1. Clinical and radiological results

\begin{tabular}{lc}
\hline \multicolumn{1}{l}{ Patients } \\
\hline Pain & $13.2 \pm 2.4(10-15)$ \\
Daily activity & $15 \pm 2.2(12-18)$ \\
Range of motion & $31.7 \pm 5.7(24-40)$ \\
Shoulder power & $21 \pm 3.5(15-25)$ \\
Final clinical result & $81.3 \pm 11.3(64-98)$ \\
Time of union in weeks & $12.5 \pm 1.6(10-17)$ \\
Alignment & \\
$\quad$ Normal & $13(76.5 \%)$ \\
$\quad$ Valgus & $2(11.8 \%)$ \\
\hline
\end{tabular}

es of secondary displacement or implant migration. Three patients complained of discomfort at the entry site of the elastic nail and thus the implants were removed after consolidation; in the other patients, removal was not necessary. CT classification of fractures coincided with the Neer Classification System, i.e., two- and three-part fractures in the CT coincided with two- and three-part fractures in the Neer Classification System; there were 12 (70.6\%) two-part fractures and and 5 (29.4\%) three-part fractures

Clinical and radiological outcomes are summarized in table 1.

\section{Discussion}

The treatment of proximal humeral fractures is problematic, especially in osteoporotic fractures. The incidence of these fractures is increasing $[16,17]$, and in the

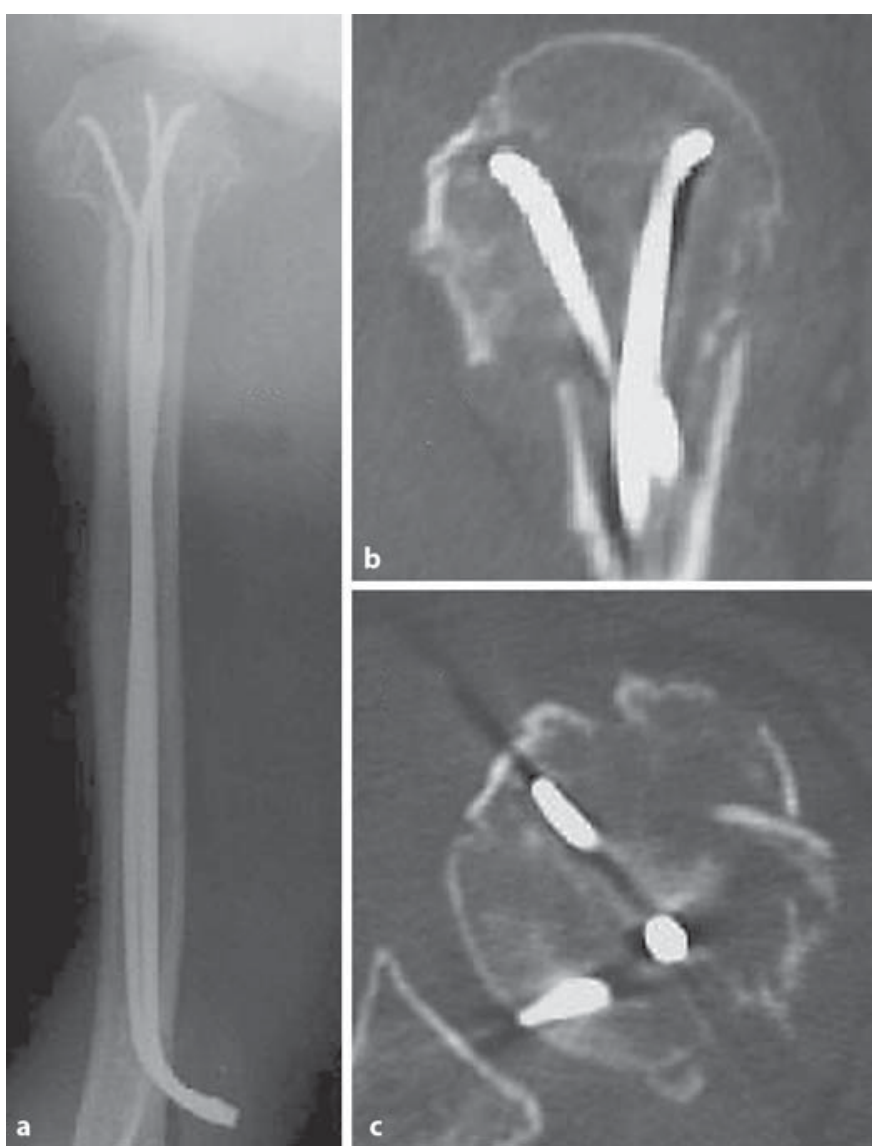

Fig. 4. Fixation of the fracture with CT. a Postoperative X-ray of two-part fracture. $\mathbf{b}$ CT in frontal plane of the same case. c CT in coronal plane of the same case.

literature of the last 10 years, renewed interest in new fixation methods of two-, three-, and four-part fractures has been observed. With the higher number of osteoporotic fractures and the increasing demand for better function- 
al outcome, new concepts and devices for treating these difficult fractures have been designed. The initial enthusiasm for locked plates, helix wire, proximal humeral locked nails and angled humeral blade plate has been moderated by reports on the high failure rate of some of these implants $[18,19]$. Biomechanical studies revealed that weak osteoporotic bone tolerates elastic implants better than stiff implants, and within a certain range of micromotion, the fracture remains stable and bone union progresses [20]. On the other hand, stiff implants, although mechanically very stable, cannot deform elastically during movements. They cut through the soft bone, causing loss of fixation and damage to remaining bone stock ('mixer effect') [21]. In our study, the initial reduction was maintained throughout the treatment period in all cases and no secondary displacement was noted. We believe that the divergent position of elastic nails in the humeral head and the impaction of the bony window distally provided sufficient stability to stimulate early passive and assisted active range of motion without jeopardizing the stability of fixation and increasing the risk of implant migration. In three-part fractures, CT was helpful in deciding upon the direction of the screws, and after surgery to confirm the reduction accuracy and position of implants in the humeral head. We did not limit the indication for the Hackethal technique to osteoporotic patients as it was applied with excellent results to both younger and older patients. It also met the criteria of min- imally invasive surgery, a current trend in modern orthopedic trauma management. The success of this fixation method may depend on elastic deformation of the implants during the healing process, stimulating consolidation of well-vascularized bone fragments. Divergent impaction of the nails that block each other in cancellous bone assures a relatively stable elastic construct. The presence of titanium, which is an osteo-inductive factor, may also play a role. In most fractures, exact anatomical reduction of fragments could not be achieved. This did not, however, affect the functional result. Improvements of minimally invasive techniques with real-time $3 \mathrm{D}$ fracture imaging and better indirect reduction tools may change this situation. Early functional treatment enabled most of our patients to have a good range of motion despite moderate displacement, an aspect of rehabilitation stressed in other studies $[22,23]$.

The major limitations of our study are the small number of patients and lack of control group for comparison.

\section{Conclusion}

The results of our study support the minimally invasive technique of elastic fixation of two- and three-part fractures of the proximal humerus as a viable alternative to other treatment methods.

\section{References}

1 Misra A, Kapur R, Maffulli N: Complex proximal humeral fractures in adults - a systematic review of management. Injury 2001 ; 32:363-372

-2 Lanting B, MacDermid J, Drosdowech D, Faber KJ: Proximal humeral fractures: a systematic review of treatment. J Shoulder Elbow Surg 2008;17:42-54.

>3 Chudik SC, Weinhold P, Dahners E, Hinsdale IL, Chapel H: Fixed-angle plate fixation in simulated fractures of the proximal humerus: a biomechanical study of a new device. J Shoulder Elbow Surg 2003;12:578588.

4 Fenichel I, Oran A, Burstein G, Perry Pritsch M: Percutaneous pinning using threaded pins treatment option for unstable two- and three-part fractures of the proximal humerus: a retrospective study. Int Orthop 2006; 30:153-157.

Hackethal Nailing for Proximal Humerus Fracture
5 Helmy N, Hintermann B: New trends in the treatment of proximal humerus fracture. Clin Orthop Relat Res 2006;442:100-108.

6 Gorschewsky O, Puetz A, Klakow A, Pitzl M, Neumann W: The treatment of proximal humeral fractures with intramedullary titanium helix wire by 97 patients. Arch Orthop Trauma Surg 2005;125:670-675.

7 Khodadadyan-Klostermann C, Raschke M, Fontes R, Melcher I, Sossan A, Bagchi K, Haas N: Treatment of complex proximal humeral fractures with minimally invasive fixation of the humeral head combined with flexible intramedullary wire fixation - introduction of a new treatment concept. Langenbecks Arch Surg 2002;387:153-160.

$>8$ Tamai K, Ohno W, Takemura M, Mashitori H, Hamada J, Saotome K: Treatment of proximal humeral fractures with a new intramedullary nail. J Orthop Sci 2005;10:180186.
9 Martin C, Guillen M, Lopez G: Treatment of 2- and 3-part fractures of the proximal humerus using external fixation. Acta Orthop 2006;77:275-278.

10 Hall J, Phieffer L, McKee M: Humeral shaft split fractures around proximal humeral locking plates: a report of two cases. J Orthop Trauma 2006;20:1-6.

11 Lill H, Hepp P, Korner J, Kassi JP, Verheyden AP, Josten C, Duda GN: Proximal humeral fractures: how stiff should an implant be? A comparative mechanical study with new implants in human specimens. Arch Orthop Traum Surg 2003;123:74-81.

12 Durbin RA, Gottesman MJ, Saunders KC: Hackethal stacked nailing of humeral shaft fractures: experience with 30 patients. Clin Orthop 1983;179:168-174.

13 Neer CS: Displaced proximal humeral fractures: classification and evaluation. J Bone Joint Surg 1970;52A:1077-1089. 
14 Edelson G, Kelly I, Vigder F, Reis ND: A three-dimensional classification for fractures of the proximal humerus. J Bone Joint Surg 2004;86B:413-425.

-15 Yian EH, Ramappa AJ, Arneberg O, Gerber C: The Constant score in normal shoulders. J Shoulder Elbow Surg 2005;14:128-133.

16 Palvanen M, Kannus P, Niemi S, Parkkari J: Update in the epidemiology of proximal humerus fractures. Clin Orthop 2006;442:8792.

17 Lee SH, Dargent-Molina P, Breart G: Risk factors for fractures of the proximal humerus: results from the EPIDOS prospective study. J Bone Mineral Res 2002;17:817-825.
Meier R, Messner P, Regazzoni P, Rothfischer W, Gross T: Unexpected high complication rate following internal fixation of unstable proximal humerus fractures with an angled blade plate. J Orthop Trauma 2006; 20:253-260.

19 Khan SA: Helix wire osteosynthesis of proximal humerus fractures: unacceptable high rate of failure. Acta Orthop Belg 2008;74: $13-16$.
20 Takeuchi R, Koshino T, Nakazawa A, Numazaki S, Sato R, Saito T: Minimally invasive fixation for unstable two-part proximal humeral fractures: surgical techniques and clinical results using J-nails. J Orthop Trauma 2002;16:403-408.

21 Hertel R: Fractures of the proximal humerus in osteoporotic bone. Osteoporos Int 2005; 16:S65-S72.

$\checkmark 22$ Hodgson S: Proximal humerus fracture rehabilitation. Clin Orthop 2006;442:131138.

23 Hodgson SA, Mawson SJ, Stanley D: Rehabilitation after two-part fractures of the neck of the humerus. J Bone Joint Surg 2003; 85B:419-422. 